\title{
Effects of Day 1 castration on aggressive behaviors of rats
}

\author{
RONALD BAENNINGER* \\ Temple University, Philadelphia, Pennsylvania 19122
}

\begin{abstract}
No rats killed mice in a group of adult male rats which had been castrated on the first day of life; in samples of intact adult males the percentages of killers were consistently between $20 \%-30 \%$. The percentage of killers among females was slightly higher than in the castrated male group. Testosterone injections had a slight effect in that three castrates began to kill after adult treatment with TP. Electric shock failed to induce stereotyped attacks on mice in castrates, who were also reliably subordinate in shock-elicited fights with intact conspecifics.
\end{abstract}

It is a common finding that males of most vertebrate species are more aggressive than females. In devising a classification system of aggressive behaviors, Moyer (1971) has found it useful to label one kind of aggression as "intermale"; there is no corresponding category called "interfemale," although Ewer (1972) reported more frequent fighting by female Rattus rattus in the wild state. On the basis of his extensive review of the relevant literature, Moyer suggested that intermale aggression is largely a function of endocrine status.

Attacks between conspecific males may be thought of as behavior which is emitted, in the sense that no stimulus other than a male conspecific is necessary for the response to appear. A different set of attack responses is emitted by some rats in the presence of mice. This interspecific aggression requires only the appearance of a mouse; a mouse-killing rat attacks and kills the first mouse presented to it as a rule, and continues to do so with decreasing latency in the absence of conventional reinforcement (Baenninger \& Ulm, 1969). In some species of rodents, adult castration reduces intermale aggression while testosterone restores the behavior (Beeman, 1947; Barfield, Busch, \& Wallen, 1972). However, when adult rats which kill mice are castrated there is no reduction in their propensity to attack and kill mice; subsequent adrenalectomy also failed to affect mouse killing (Karli, 1958). This result could mean either that intermale aggression differs in kind from mouse-killing, as Moyer believes, or it could mean that both kinds of aggressive behavior have neuroendocrine bases which, while similar, may be differentially affected by surgical insult in adulthood. That is, castration in adulthood may cause different effects on the two types of aggression; infant castration might result in similar effects.

The failure to abolish mouse-killing in adults by castration may have resulted from the fact that early presence of testosterone results in characteristic male aggressive behavior, which is not modified by subsequent removal of androgen sources. Feminization of sexual

*These results were presented at the meeting of AAAS in Philadelphia, December 1971. I thank William Miley for his surgical and data collection work. behavior results when male rats are neonatelly castrated, but not when castration is performed in adulthood. It was hypothesized in the present experiment that neonatal castration would result in abolition of adult mouse-killing behavior, and that adult testosterone administration to neonatally castrated rats would result in little or no increase in their aggressive behavior.

Aggressive behavior is emitted by some organisms. However, it is also possible reliably to elicit aggressive behavior of various kinds in adult organisms which are painfully stimulated while in pairs in a small enclosure. While one may argue about whether the upright "boxing" posture which rats show in this situation is really aggressive (Reynierse, 1971), it has been shown that vicious biting attacks also occur in this situation, and that dominance relationships may be reliably determined (Baenninger \& Grossman, 1969; Reynierse, 1971). As a way of discovering whether mouse-killing and pain-elicited fighting were similarly affected by neonatal castration, neonatally castrated rats were placed together with intact rats in a pain-elicited aggression situation. This procedure in the present experiment allowed for a preliminary comparison of the effects of a single manipulation (hormonal status) on both emitted and elicited aggressive behavior.

\section{METHOD}

\section{Subjects, Surgery and Rearing Conditions}

Sixty male and 57 female Long Evans rat pups served as Ss. An additional group of 150 males of the same strain, which were identically reared, provided additional control data. On Day 1 postpartum 30 male Ss were castrated. After weaning at 21 days postpartum, castrate male Ss were housed with at least one female and/or an intact control male of the same age, to form groups of 2 or 3 rats. Control males were not surgically insulted.

\footnotetext{
Procedures

On Days 90 and 91, all experimental, control, and female Ss were tested individually for $1 \mathrm{~h}$ with an albino mouse.

Beginning of Day 120, after a single 1-h test with a mouse, daily injections of castrated male Ss and females with $0.2 \mathrm{mg}$ of testosterone propionate in $0.1 \mathrm{cc}$ sesame oil were given for 6 days, but no mice were presented during this time. On the seventh day (Day 126) a mouse was presented individually to each S.
} 
When males in the experimental group were 175 days of age, they were given two experiences with electric shock in the presence of a mouse. A mouse was presented to each rat in its living cage; $2 \mathrm{~min}$ later, a $1.9-\mathrm{mA}$ shock was delivered to its feet in a 5-sec on, 5-sec off pattern for $1 \mathrm{~min}$. The mouse was removed $2 \mathrm{~min}$ later. On the following 2 days, the same procedure was followed except that an intact male rat from the control group was placed with each experimental S, instead of a mouse. Presence of stereotyped fighting and biting was scored before, during, and after shock. The occurrence was also scored of postures in which one rat rolled onto its back while its opponent placed forepaws on its stomach in the dominance posture. Unless each S consistently behaved in either the dominant or submissive manner no winner was scored.

\section{RESULTS}

Death and cannibalism by the mother required that 223 infant males were castrated in order to have 30 experimental Ss. That all castrations were complete was suggested by the fact that none of the females, with whom Ss lived until 175 days of age, ever became pregnant.

None of the 30 experimental males killed a mouse in either test on Days 90 and 91 . By contrast, 6 out of 30 intact littermate control males $(20 \%)$ attacked mice in the stereotyped manner first described by Karli (1956). Out of a sample of 150 intact males of similar hereditary background, which were born and reared in the Temple laboratory, 44 attacked mice reliably (29\%). One female killed one mouse. While sampling variation does exist, it appears clear that Day 1 castration abolished the propensity to kill mice in rats which would otherwise have had a considerably higher probability of killing.

After 6 days of testosterone propionate injections, 3 of the 27 surviving experimental rats killed mice (11\%), although none had killed originally; two of the females killed; none of the remaining castrates or females showed any signs of attacking mice. Two out of 53 surviving female Ss began to kill mice after injections. Thus, about $4 \%$ of females apparently were induced to kill mice by testosterone propionate.

Under the influence of electric shock several castrates bit mice. These attacks were not reliable and were not performed in the natural stereotype manner shown by killers. In tests for pain-elicited fighting with intact control rats, the castrated animal was virtually always subordinate where a clear winner emerged. Castrates did fight, showing both biting and the stereotyped fighting posture followed in some cases by hissing (Berg \& Baenninger, 1973), but were apparently unable to achieve dominance over their intact opponent.

\section{DISCUSSION}

Mouse killing never was shown without supplementary testosterone. Attacks on mice which were elicited by painful electric shock were unreliable and lacking in directedness in Day 1 castrates. Although they still fought with conspecifics when shocked, the behavior of castrates was in some way subtly modified so that they emerged as reliably subordinate in these pair encounters.

Since no pretest was possible before perinatal castration, it is impossible to determine the percentage of experimental group animals which would have been killers had they not been castrated. Based on control data, and other data from animals raised in the Temple laboratory, it seems safe to expect between $20 \%$ and $30 \%$ of a male sample to be killers as adults. That none of the castrates killed in the first two tests at an age when the propensity to kill mice has usually made its appearance suggests that perinatal castration abolished this form of aggressive behavior and "feminized" males in the sense that they behaved like female littermates toward mice.

The effect of testosterone injections is difficult to interpret. None of the control animals which failed to kill at 90-91 days began to kill at 120 days; this indicates that the castrate males, and females which begin to kill after the TP injection series did so because of the TP, and not because of some process correlated with aging or mere exposure to mice on two prior occasions. But neither of these groups presumably, 'ad that appropriate substrate, which normally develops in intac: males as a consequence of perinatal testicular androg, is, and which enables such males to be responsive to adult androgens.

Rosenberg, Denenberg, Zarrow, and Frank ( 971$)$ found that neonatal castration reduced the percentage of the male rats which killed rat pups in adulthood, but that castrating males in adulthood does not diminish pup killing responses. This pattern of results is highly similar to that of the present experiment, and suggests that the mouse-killing and pup-killing responses may result from a common hormonal basis in infancy. So-called "predatory" aggression has been differentiated from "intermale" aggression by Moyer (1971) because of mirimal effects of hormone status in the former, compared to the latter. The present results, together with those of Rosenberg et al (1971), suggest that such a distinction may be unwarranted.

\section{REFERENCES}

Baenninger, R., \& Grossman, J. C. Some effects of punishment on pain-elicited aggression. Journal of the Experimental Analysis of Behavior, 1969, 12, 1017-1022.

Baenninger, R., \& Ulm, R. R. Overcoming the effects of prior punishment on interspecies aggression. Journal of Comparative \& Physiological Psychology, 1969, 69, 628-635.

Barfield, R. J., Busch, D. E., \& Wallen, K. Gonadal influence on agonistic behavior in the male domestic rat. Hormones \& Behavior, 1972, 3, 247-259.

Beeman, E. A. The effect of male hormone on aggressive behavior in mice. Physiological Zoology, 1947, 20, 373-405. Berg, D. S., \& Baenninger, R. Hissing by laboratory rats during fighting encounters. Behavioral Biology, 1973, 8, 733-741.

Ewer, R. E. The biology and behaviour of a free-living population of black rats (Rattus rattus). Animal Behaviour Monographs, $1971,4,127-174$.

Karli, P. The Norway rat's killing response to the white mouse: An experimental analy sis. Behaviour, 1956, 10,81 .

Karli, P. Hormones steroides et comportement d'aggression interspecifique Rat-souris. Journal de Physiology (Paris), $1958,50,346$.

Moyer, K. E. A preliminary physiological model of aggressive behavior. In B. E. Eleftheriou and J. P. Scott (Eds.) The physiology of aggression and defeat. New York: Plenum Press, 1971.

Reynierse, J. H. Submissive postures during shock-€licited aggression. Animal Behaviour, 1971, 19, 102-107.

Rosenberg, K. M., Denenberg, V. H., Zarrow, M. X., \& Frank, B. L. Effects of neonatal castration and testosterone on the rat's pup-killing behavior and activity. Physiology \& Behavior, 1971, 7, 363-368.

(Received for publication Deceinber 5, 1973.) 